\title{
AUTO-REGULATORY NEUROMECHANISM OF THE TONGUE MUSCLE ACTIVITY
}

\author{
Yojiro Kawamura, Masaya Funakoshi, Tooru Nishiyama \\ AND Toshifumi MoRIMOTO \\ Department of Oral Physiology, Dental School, \\ Osaka University, Osaka, Japan
}

Tongue muscles are non-joint moving muscles and consist of extrinsic and intrinsic muscle groups. Contraction of the extrinsic tongue muscle group can produce fast movements of the tongue for protrusion, retraction or lateral deviation, and contraction of the intrinsic muscle group may produce a delicate change in shape of the tongue. The tongue is constantly in action during mastication, deglutition and speech, and the basic physiologic mechanisms of such well organized fine movements of the tongue might be attributed to some reflex system. However, there are still many discussions on the detailed physiologic mechanisms of such a system. Especially, the proprioceptive innervation of the tongue except in humans is still not clear, in spite of many morphological studies ${ }^{3,4,5,6,10,21,25,29)}$.

In the present experiment, cats were used and three different procedures were carried out to clarify the neural feedback system controlling tongue muscle activities. The first was an analysis of individual tongue muscle activity, the second a recording of afferent nerve impulses from the tongue, and the third a recording of the response in the medulla induced by stretch of the tongue.

\section{METHODS}

1. Electromyographic analysis: Twelve decerebrate cats were used in this experiment. The head of the animal was rigidly fixed in a frame by a clamp. A cotton thread was connected to the tip of tongue to stretch the tongue with various loads through a pulley system, and the movement of tongue was recorded by a force displacement transducer (FTO 3, Grass Instrument Co.). Electrical activities of the tongue muscles were recorded by a fine concentrated needle electrode at the resting state and also during stretch of the tongue. After recording, the site of the recording electrode tip was electrically coagulated $(1 \mathrm{~mA}, 30$ seconds) and histologically verified.

Received for publication July 21, 1966 河村洋二郎, 船越汇山, 西山亨, 森本俊文 
2. Single fiber analysis: Fifteen adult cats were used in this experiment. Animals were anesthetized with Nembutal-soda $(40 \mathrm{mg} / \mathrm{Kg})$. The central connection of the lingual or glossopharyngeal nerve was cut, and a peripheral end of the nerve was carefully dissected under observation through a stereoscopic microscope to get a functional single unit of the nerve fiber. A monopolar platinum electrode $(0.2 \mathrm{~mm}$ in diameter) was used for the record of nerve discharges and a small silver round plate $(5 \mathrm{~mm}$ in diameter) was fixed to the surrounding tissue as an indifferent electrode. The response of the nerve fiber in the lingual or glossopharyngeal nerve to stretch of the tongue was recorded.

3. Medullary projection of the tongue afferents: Nine adult cats were used, these were decerebrate and decerebellate animals prepared under Nembutal anesthesia (30 $\mathrm{mg} / \mathrm{Kg}$ ). The head of the cat was fixed in a Johnson type stereotaxic apparatus. The surface of the exposed medulla was covered with liquid paraffin kept at $38^{\circ} \mathrm{C}$. A silver microelectrode enclosed in a fine glass pipette ( $20 \mu$ or less at the tip diameter) was inserted stereotaxically into the medulla to search for the spots responding to tongue stretching and electrical activity of the spots was analysed. Insertion of the recording electrode was directed by SNIDER and NIEMER's brain map ${ }^{26)}$. After the experiment, the site of the recording electrode tip in the brain was histologically verified.

\section{RESULTS}

1. Tongue muscle phenomena: As shown in FIG. 1, spontaneous activity was detectable in some spots in the tongue even at rest position, although there

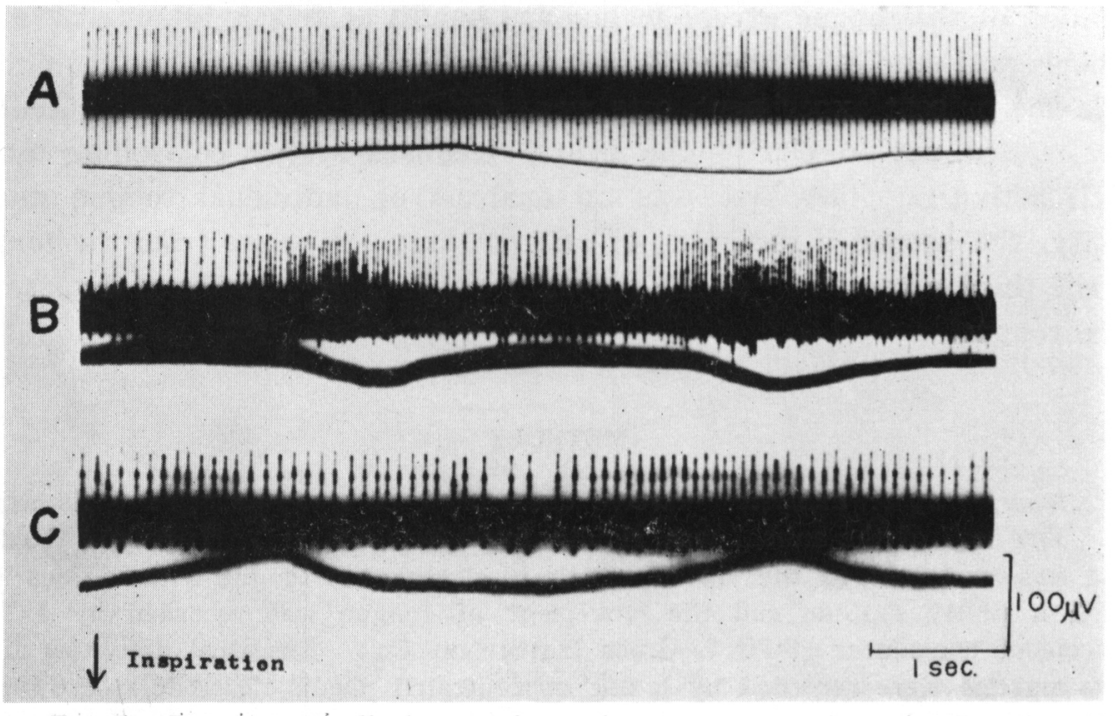

FIG. 1. Spontaneous discharges from the tongue muscles. A: Regular 17 spikes/sec discharges without any relation with the respiratory movement. B: 11 spikes/sec discharge in expiration increased to 28 spikes/sec during the inspiratory phase. C: Discharge frequency of $7 \mathrm{spikes} / \mathrm{sec}$ in inspiration increased to 13 spikes/sec during expiratory phase. Upper; EMG. Lower : Respiratory movement. 
were many spots without spontaneous electrical activity. These spontaneous discharges were about $100-500 \mu \mathrm{V}$ in amplitude and about $3 \mathrm{msec}$ in spike duration. Some of these activities were regular and continuous as shown in the upper trace in FIG. 1, but some fluctuated corresponding to the respiratory phase as shown in the second and third trace.

The spots showing regular-type spontaneous discharges widely distributed all over the tongue (open circle in FIG. 2), however, the spots showing the fluctuated-type discharges were detected only in some definite tongue muscles.
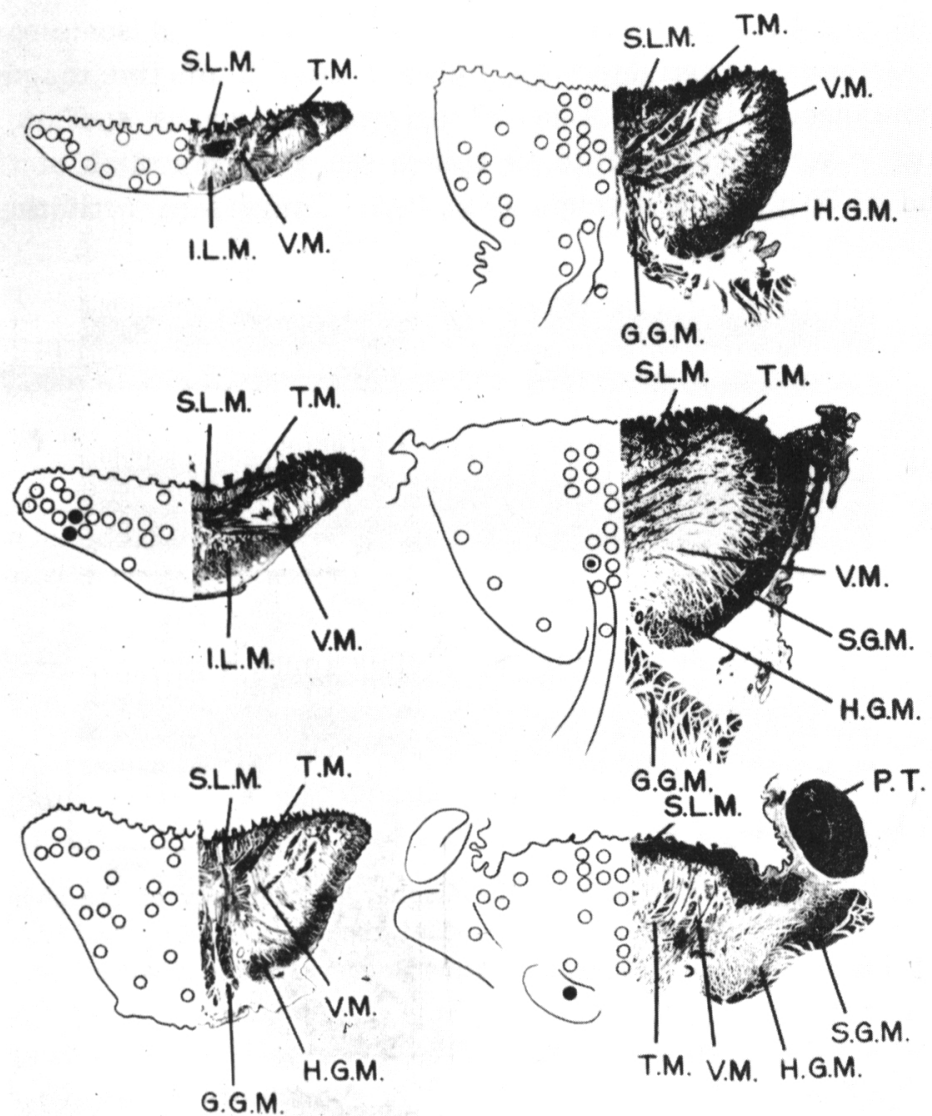

FIG. 2. Schematic diagrams indicating distribution of three types of spontaneously discharging neuro-muscular units in the coronal section of the tongue. Open circle: Regular type (FIG. 1, A), Solid circle: Inspiratory activated type (FIG. 1, B), Double circle: Expiratory activated type (FIG. 1, C). S. L. M. : Superior longitudinal muscle, I. L. M. : Inferior longitudinal muscle, T.M.: Transverse muscle, V. M.: Vertical muscle, G.G. M.: Genioglossus muscle, H. G. M.: Hyoglossus muscle, S. G. M. : Styloglossus muscle. 
The spots (solid circle in Fig. 2) at which the frequency of discharge increased during the inspiratory phase, were recognized mostly in the tongue retractors such as the styloglossus, hyoglossus and longitudinal muscles, while the other spots at which the frequency of discharge decreased during the inspiratory phase (double circle in FIG. 2) were observed in tongue protruders such as the genioglossus muscle.

In the next step of the experiment, influence of forward stretch of the tongue on the tongue muscle activity was investigated. Although there were many spots in the tongue muscles which did not display any responses to forward stretch of the tongue, some spots in the tongue muscles were strongly effected by this procedure. Electrical activity of some spots in the tongue retractors was activated by forward stretch of the tongue, that is, regular spontaneous discharges of 12 spikes/sec from a spot in the styloglossus muscle were activated to 19 spikes/sec during stretch of the tongue with a load of $50 \mathrm{~g}$ for 3 seconds (FIG. 3A). Conversely, activities of some

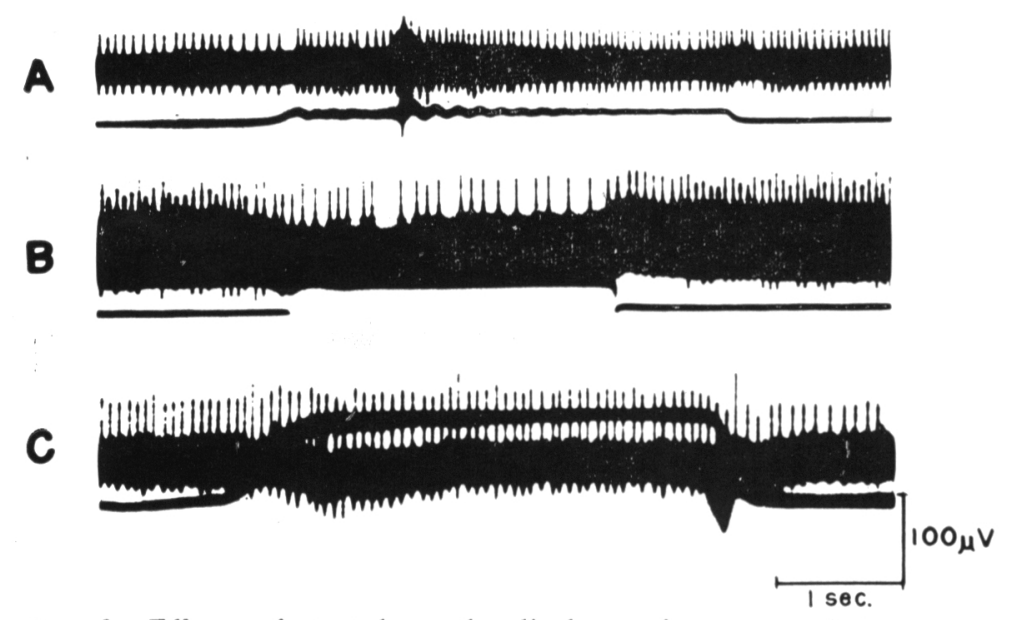

Fig. 3. Effects of stretch on the discharge frequency of the spontaneously discharging neuro-muscular unit of the tongue. A: Discharge frequency increased. B: Discharge frequency decreased. C: No effect.

spots in the tongue protruders were inhibited by the same procedure. In FIG. 3B, the spontaneous discharges of 16 spikes/sec from the transverse lingual muscle were decreased to 8 spikes/sec during stretch of the tongue with a load of $100 \mathrm{~g}$. This stretch reflex of the tongue was not abolished by anesthesia of the tongue surface with xylocaine spray, however, the reflex was completely abolished after dissection of the ipsilateral lingual or glossopharyngeal nerve. The muscle activity recorded from the frontal part of the tongue was abolished after section of the ipsilateral lingual nerve and that from the posterior part of the tongue was abolished after section of the ipsi- 
lateral glossopharyngeal nerve. These facts suggest that these responses originate from some deep mechanoreceptors within the tongue and that afferent impulses from these mechanoreceptors are transmitted to the brain via the ipsilateral lingual and glossopharyngeal nerves.

2. Peripheral and central phenomena: The afferent nerve route for this tongue stretch reflex was studied by a single nerve fiber analysis. A small number of fibers within the lingual and glossopharyngeal nerves of the cat responded to tongue stretching. The response of the nerve fiber was slow adaptive and sustained its activity during stretch of the tongue. One sample recorded from a lingual nerve fiber is shown in FIG. 4. Six spikes/sec of spontaneous discharge of this fiber were accelerated to 12 spikes/sec by $7 \mathrm{~mm}$ forward stretch of the tongue, and this acceleration of discharge continued during 2 seconds of stretching. A similar type of nerve fiber was also detected in the glossopharyngeal nerve. Activities of these nerve fibers were not

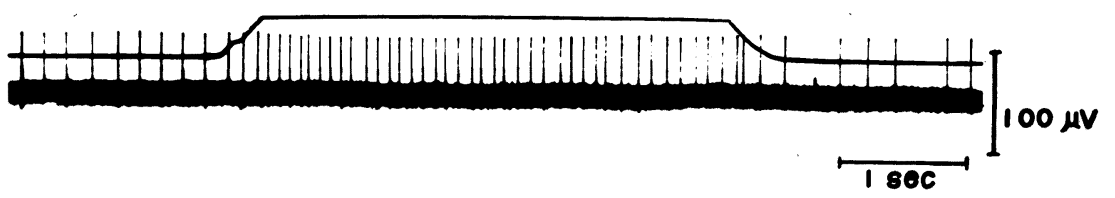

Fic. 4. Acceleration in spontaneous discharge of a single fiber in the lingual nerve induced by forward stretch of the tongue. Upper trace: Tongue movement, Lower trace: Electrical activity of the nerve fiber.

affected at all by anesthesia of the tongue surface with a $10 \%$ xylocaine spray. Touch, pressure and taste stimuli did not elicit any responses of these nerve fibers. Frequency of discharge from these nerve fibers was increased in proportion to intensity of tongue stretching. These facts indicate that some sensory information from the deep mechanoreceptors in the tongue concerning muscle extension is transmitted through some fibers in the glossopharyngeal and lingual nerves.

In the next step of this experiment, central projections of these impulses from the deep mechanoreceptors of the tongue and the response of the hypoglossal nucleus to stretch of the tongue were studied.

There were spots in the medulla which increased their activity responding to stretch of the tongue. The distribution of these spots in the medulla is shown in FIG. 5 as solid circles. Most of them localized in the sensory nucleus of the trigeminal nerve, in the nucleus of the solitary tract, in the dorsal nucleus of the vagus, in the bulbar reticular formation and in the nucleus of the hypoglossal nerve. Among 48 spots recorded from the sensory nucleus of the trigeminal nerve, 13 spots showed a slow adaptive response to stretch of the tongue, 5 spots showed a transient response while the remain- 

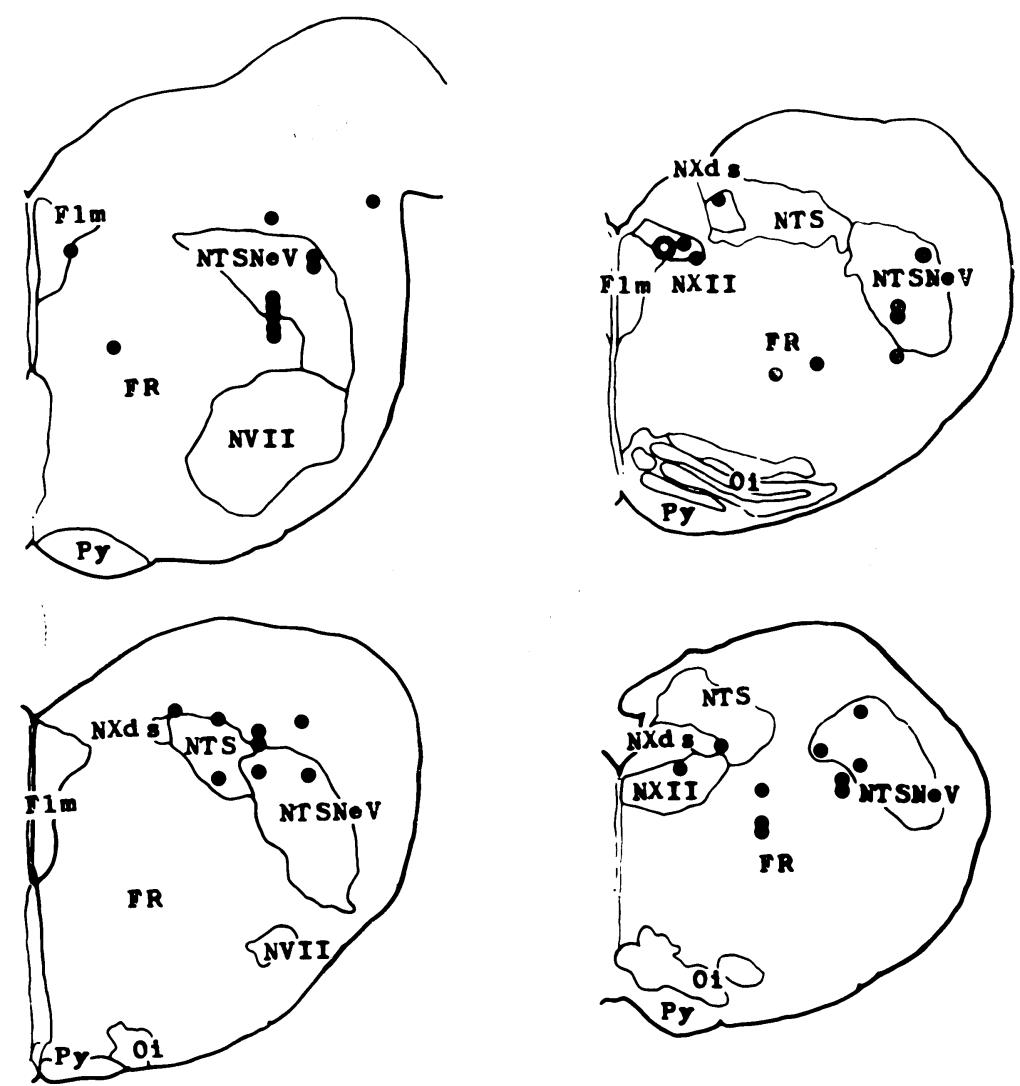

FIG. 5. Schematic diagram of the distribution of spots in the medulla which responded to forward stretch of the tongue. Solid circle: Spot with facilitatory response, Open circle: Spot with inhibitory response. NTSNeV : Nucl. tract. spinalis n. trigemini, N VII : Nucl. n. facialis, NXds : Nucl. dorsalis n. vagi, N XII: Nucl. n. hypoglossi, NTS: Nucl. tractus solitarii, Oi : Nucl. olivaris inferior, Flm: Fasciculus longitudinalis medialis, FR : Formatio reticularis, Py: Pyramis.

ing 30 spots did not respond to stretch of the tongue. Four among 47 recorded spots in the nucleus of the solitary tract responded to stretch of the tongue. Other 3 spots showed a transient response and the remaining 40 spots did not respond at all. In the dorsal nucleus of the vagus 2 among 32 recorded spots also facilitated their activities as response to stretch of the tongue, but other 30 spots did not respond to the procedure. Also 17 spots among the recorded 180 spots in the bulbar reticular formation responded to stretch of the tongue. FIG. 6 is the record from a spot in the ventrolateral part of the dorsal nucleus of the vagus, at $3.0 \mathrm{~mm}$ rostral to the obex, $2.0 \mathrm{~mm}$ lateral to the midline and $0.5 \mathrm{~mm}$ ventral to the bulbar surface. About 3 spikes/sec of spontaneous discharge of this spot were gradually accelerated 


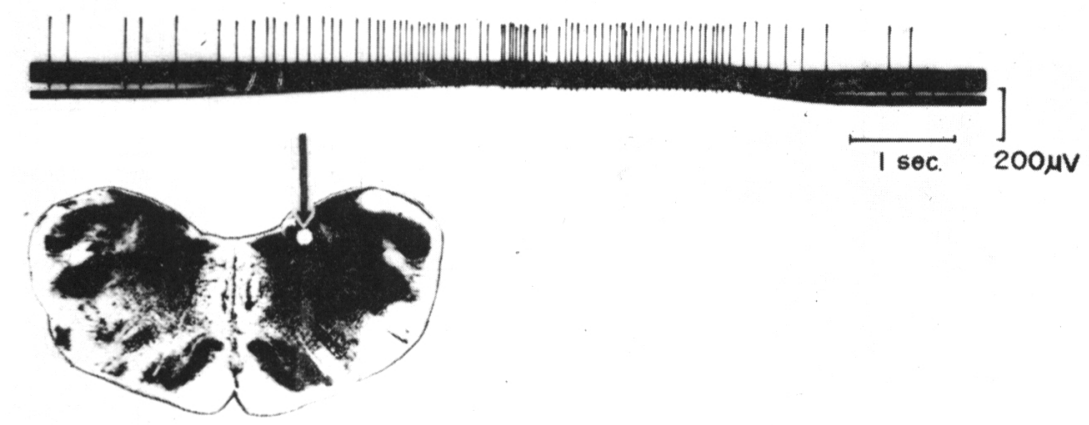

FIG. 6. Facilitation at a spot in the dorsal nucleus of the vagal nerve. Upper trace: Electrical activity, Lower: Tongue movement. Arrow in the histologic section indicates the position of the recording electrode in the nucleus.

up to 16 spikes/sec when the tongue was pulled forward with a $100 \mathrm{~g}$ load. When the load for tongue stretching was released the acceleration stopped and the activity soon returned to the resting level.

Among 31 spots recorded in the hypoglossal nucleus only 3 spots responded to stretch of the tongue. Fig. 7 is the record from one spot in the hypoglossal nucleus, at $2.5 \mathrm{~mm}$ rostral to the obex, $1.0 \mathrm{~mm}$ lateral to the midline and $1.0 \mathrm{~mm}$ ventral to the surface. This spot showed about $9 \mathrm{spikes} / \mathrm{sec}$ of discharge during stretch of the tongue.

In addition, the activity of another spot in the hypoglossal nucleus with a spontaneous discharge of 13 spikes/sec was inhibited by stretch of the ton-

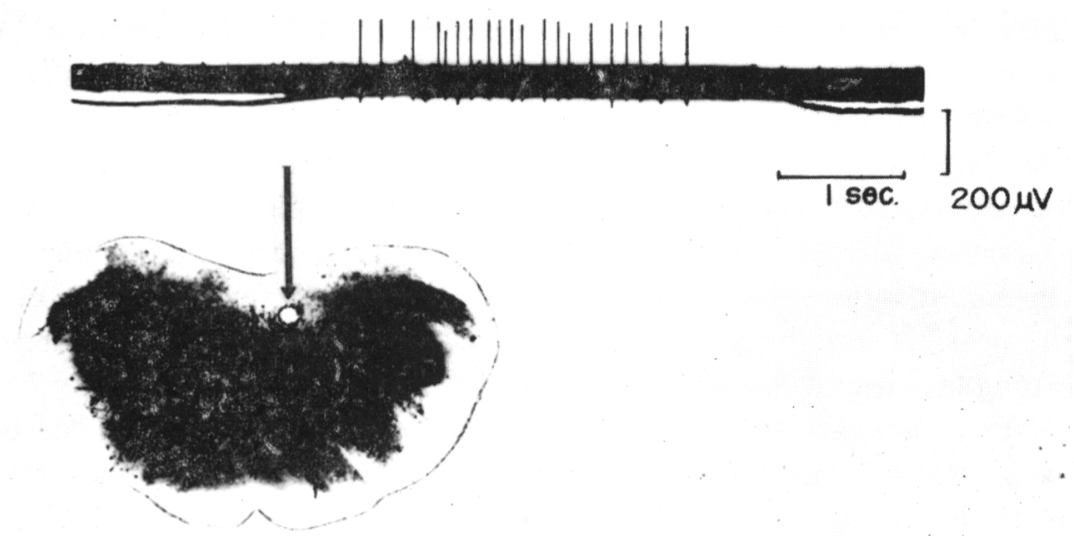

Fig. 7. Facilitation at a spot in the nucleus of the hypoglossal nerve. Upper trace: Electrical activity, Lower trace: Tongue movement. Arrow in the histologic section indicates the position of the recording electrode in the nucleus. 


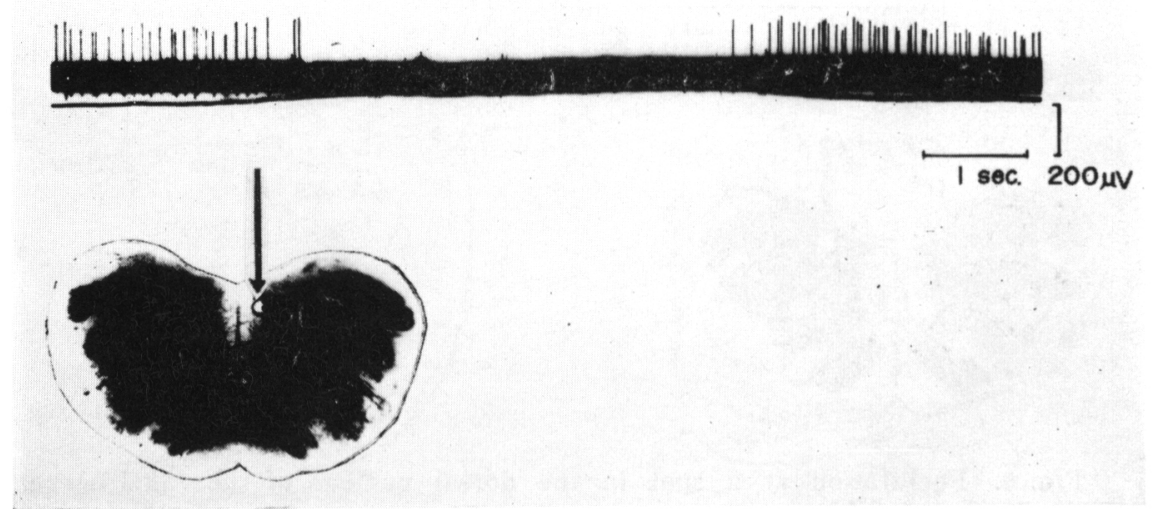

FIG. 8. Inhibition at a spot in the nucleus of the hypoglossal nerve. Upper trace: Electrical activity, Lower trace: Tongue movement. Arrow in the histologic section indicates the position of the recording electrode in the nucleus.

gue (FIG. 8). This inhibitory response was recorded from a spot at $1.9 \mathrm{~mm}$ rostral to the obex, $0.7 \mathrm{~mm}$ lateral to the midline and $0.5 \mathrm{~mm}$ ventral to the surface (also indicated as open circle in FIG. 5).

\section{DISCUSSION}

Neural information from the exteroceptors of tongue surface mostly participates within the reflexes controlling the tongue muscle activity. However, in addition to this exteroceptive reflex mechanism of the tongue, our present findings also imply the existence of some myotatic reflex of the tongue.

There is controversy concerning the existence of muscle spindles in the tongue that could provide proprioceptive sensation. Some investigators reported the presence of muscle spindles in the human or animal tongue, but some reported that they could not recognize muscle spindles in the tongue muscle.

Recently $\mathrm{BLOM}^{3)}$ reported the absence of muscle spindles in both intrinsic and extrinsic muscles of the cat's tongue. Other reports have shown a few atypical endings situated in the genioglossal muscle ${ }^{4,80}$, and presumably indicate the possible exsistence of some other type of receptors for proprioception in the tongue muscles.

CoOPER ${ }^{6)}$ demonstrated afferent impulses in the hypoglossal nerve on stretching the cat's tongue. Thus it appeared that some kind of muscle sensation will be transmitted to the hypoglossal nucleus in the medulla. GREeN and NEGISHI ${ }^{15)}$ suggested that the hypoglossal nucleus was possibly influenced by another afferent system rather than by the hypoglossal nerve itself. At any rate, there must be some sensory feedback system to control tonus and movements of the tongue, since the tongue can perform very fine and skilful 
movements.

According to $\mathrm{BLOM}^{3)}$, electrical activity of the tongue muscle was not recorded at all either at rest condition of the tongue or during stretch of the tongue in decerebrate cats. In our present results most of the spots in the tongue muscle also did not show spontaneous discharges and also did not respond to stretch of the tongue. However, contrary to Blom's findings some fibers of the tongue muscles showed spontaneous electromyographic discharge and among them some increased the discharge frequency in response to stretch of the tongue.

$\mathrm{LEI}^{22)}$ observed that the tongue muscles of the cat or guinea pig contracted when the animal was in asphyxia, and he named this phenomenon "respiratory tongue contraction". $\mathrm{BLOM}^{3)}$ also observed "respiratory tongue contraction" under augmented respiration in the cat. EMG recording in our present experiment revealed that activities of some of the tongue muscles showed respiratory fluctuation even during normal respiration. These facts suggest that impulses from the respiratory center may effect the activity of some motor neurons in the hypoglossal nucleus and this mechanism might influence the tongue movement during respiration.

The stretch response of the tongue which was detected in this experiment may be attributed to excitation of deep mechanoreceptors in the tongue, because this response was not affected by anesthesia of the tongue surface but abolished after dissection of the lingual or glossopharyngeal nerve. On the other hand, CORBIN and HARRISON ${ }^{11}$ reported that afferent impulses from the tongue stretch receptors were transmitted through the ventral branch of $\mathrm{C}$, and $\mathrm{COOPER}^{6)}$ and $\mathrm{BLOM}^{3)}$ postulated the hypoglossal nerve as a muscle afferent from the tongue, while BARRON ${ }^{2)}$ emphasized the lingual nerve as a tongue muscle afferent. In their reports, however, they only described briefly the phenomenon of these tongue afferent impulses with no further detail. FITZGERALD and $\mathrm{LAW}^{13}$ ) found peripheral connections between the lingual and hypoglossal nerve in the cat and they implied that CoOPER's finding ${ }^{6}$ ) appeared to be in conformity with the communication between the lingual and hypoglossal nerves. Our present results revealed that the lingual and glossopharyngeal nerves contained a few fibers which transmit the impulses referring to stretch of the tongue.

When preparing this report for publication the recent work of PORTER ${ }^{24)}$ came to our knowledge. He also recorded afferent discharges from the lingual nerve responding to stretch of the tongue and found that stretch of the tongue excited some of the presumed deeply situated slowly adapting endings in the tongue. His findings coincide well with our previous ${ }^{20)}$ and present results.

HosoKAW ${ }^{16)}$ pointed out a lack of typical muscle spindles in most of the cranial muscles, where only atypical, rather primitive types of endings are 
found with individual variations in shape. It is still unknown whether the receptors responding to stretch of the tongue are typical muscle spindles or a different type of deep mechanoreceptors.

Afferent impulses from the muscle spindles in the jaw muscles ${ }^{7,9,11,17,18)}$ and eye muscles ${ }^{7,12,14,23,28)}$ are projected into the mesencephalic nucleus. SzENTA GOTHAI ${ }^{27)}$ reported that collaterals of the mesencephalic neuron reached the hypoglossal neurons. Therefore, we may speculate that afferent impulses from the deep mechanoreceptors of the tongue muscle also possibly project into the mesencephalic nucleus. However, according to CoRBIN ${ }^{9)}$ no degenerated fibers were recognized in the lingual, glossopharyngeal, vagal and hypoglossal nerves after dissection of the mesencephalic root. Further, our present results showed that spots responding to stretch of the tongue were mostly localized in the sensory nucleus of the trigeminal nerve, in the nucleus of the solitary tract, and in the dorsal nucleus of the vagal nerve. The bulbar projection of the impulses from the deep mechanoreceptors in the tongue, therefore, differs from that of the jaw muscles. Information from the deep mechanoreceptors in the tongue projects to the medulla as well as the propriocepting impulses from the jaw joint capsule ${ }^{19}$.

In this experiment, facilitatory and inhibitory responses responding to stretch of the tongue were recorded in the hypoglossal nucleus. Concerning the facilitatory response of the hypoglossal neuron, GREEN and NEGISHI ${ }^{15)}$ also reported that two neurons among examined fifty neurons of the cat were activated by stretch of the tongue, and they speculated that this facilitatory response was possibly attributed to exteroceptive impulses from the tongue. However, through our present experiments, we imply that impulses from the deep mechanoreceptors (proprioceptors) in the tongue play a part of this facilitatory phenomenon.

An inhibitory response was also recorded in the cat from the medioventral part of the hypoglossal nucleus when we stretched the tongue. The motoneurons innervating the genioglossal muscle, which is one of the tongue protrusive muscles, mostly distribute in this region of the hypoglossal nucleus ${ }^{1)}$. Therefore, this inhibitory response may be concerned with a feedback phenomenon preventing an excessive protrusion of the tongue.

\section{SUMMARY}

The neural feedback system controlling tongue muscle activities was studied in the decerebrate cat.

Spontaneous activities were detected from some muscular fibers of the tongue. The discharges of some fibers in the tongue retractors were increased and those in the tongue protruders were decreased by forward stretch of the tongue. These responses were not affected by anesthesia of the tongue 
surface. However, the responses completely disappeared after dissection of the lingual or glossopharyngeal nerve.

In the lingual and glossopharyngeal nerves, a few fibers were detected to respond to stretch of the tongue. This response was slowly adaptive and the frequency of impulses from the nerve fibers was increased in proportion to the intensity of tongue stretching.

The activity of several spots in the sensory nucleus of trigeminal nerve, in the nucleus of solitary tract, in the dorsal nucleus of vagal nerve, in the bulbar reticular formation and in the nucleus of hypoglossal nerve was activated by stretch of the tongue. On the contrary, the activity of some spots in the hypoglossal nucleus was inhibited.

This investigation was supported by Public Health Service Research Grant DE-01718, from the National Institute of Dental Research, National Institutes of Health, Bethesda, Maryland, U.S. A.

\section{REFERENCES}

1) Barnard, J.W. The hypoglossal complex of vertebrates. J. Comp. Neurol. 72 : 489-524, 1940.

2) BARRon, D. H. A note on the course of the proprioceptor fibers from the tongue. Anat. Record, 66 : 11-15, 1936.

3) BLOM, S. Afferent influences on tongue muscle activity; A morphological and physiological study in the cat. Acta Physiol. Scand. Suppl. 170: 1-97, 1960.

4) Boyd, J.D. The sensory component of the hypoglossal nerve in the rabbit. $J$. Anat., London 75 : 330-347, 1941.

5) CARLEton, A. Observations on the problem of the proprioceptive innervation of the tongue. J. Anat., London, 72: 502-507, 1938.

6) COOPER, S. Afferent impulses in the hypoglossal nerve on stretching the cat's tongue. J. Physiol., London. $126: 32$ p., 1954.

7) Cooper, S., Daniel, P.M. and Whitteridge, D. Nerve impulses in the brain stem of the goat. Short latency responses obtained by stretching the extrinsic eye muscles and the jaw muscles. J. Physiol., London, 120: 471-490, 1953.

8) Cooper, S., Daniel, P.M. And Whitteridge, D. Muscle spindles and other sensory endings in the extrinsic eye muscles: The physiology and anatomy of these receptors and of their connections with the brain-stem. Brain, 78: 564-583, 1955.

9) CoRBIN, K. B. Observations on the peripheral distribution of fibers arising in the mesencephalic nucleus of the fifth cranial nerve. J. Comp. Neurol. 73: 153-177, 1940.

10) Corbin, K. B. And Harrison, F. Further studies on tongue innnervation. Proc. Soc. Exp. Biol. Med. 38 : 308-310, 1938.

11) Corbin, K. B. AND Harrison, F. Function of the mesencephalic root of the fifth cranial nerve. J. Neurophysiol. 3: 423-435. 1940.

12) Fillenz, M. Responses in the brainstem of the cat to stretch of extrinsic ocular muscles. J. Physiol., London, $128: 182-199,1955$.

13) Fitzgerald, M.J.T. And Law, M.E. The peripheral connexions between the lingual and hypoglossal nerve. J. Anat., London, 92: 178-188, 1958.

14) Freeman, W. The relationship of the radix mesencephalica trigemini to the ex- 
traocular muscles. A.M. A. Arch. Neurol. Psychiat. $14: 111-113,1925$.

15) Green, J.D. ANd Negishi, K. Membrane potentials in hypoglossal motoneurons. J. Neurophysiol. 26 : 835-856, 1963.

16) Hosokawa, H. Proprioceptive innervation of striated muscles in the territory of cranial nerves. Texas Rept. Biol. Med. 19: 405-464, 1961.

17) Johnston, J. B. The radix mesencephalica trigemini. J. Comp. Neurol. 19: 593644, 1909.

18) Kawamura, Y., Funakoshi, M., Tsukamoto, S. and Takata, M. Brain stem mechanisms controlling the jaw muscle-tonus of the dog. Japan. J. Physiol. 9: 453-463, 1959.

19) Kawamura, Y. ANd Majima, T. Temporomandibular-joint's sensory mechanisms controlling activities of the jaw muscles. J. Dental Res. $43: 150$ p., 1964.

20) Kawamura, Y., Funakoshi, M., Nishiyama, T. and Majima, T. Afferent impulses from tongue for autogenetic regulation of tongue muscle activity. J. Physiol. Soc. Jap. 27 : 436-445, 1965. (in Japanese)

21) LANGworthy, O.R. A study of the innervation of the tongue musculature with particular reference to the proprioceptive mechanism. J. Comp. Neurol. 36:273297, 1924.

22) LEI, L. Irradiation of excitation from the respiratory center to motor centers for muscle of the tongue. J. Physiol. USSR, 47: 906-912, 1961.

23) Pearson, A. A. The trochlear nerve in human fetuses. J. Comp. Neurol. $78: 29$ 43, 1943.

24) Porter, R. Lingual mechanoreceptors activated by muscle twitch. J. Physiol., London, 183 : 101-111, 1966.

25) Sherrington, C.S. On the anatomical constitution of nerves of skeletal muscles; with remarks on recurrent fibers in the ventral spinal root. J. Physiol., London, 17: 211-258, 1894.

26) Snider, R.S. And Niemer, W.T. A stereotaxic atlas of the cat brain. The University of Chicago Press, Chicago, 1961.

27) Szentágothai, J. Anatomical considerations of monosynaptic reflex arcs. $J$. Neurophysiol. 11: 445-454, 1948.

28) Tarkhan, A. A. The innervation of the extrinsic ocular muscles. J. Anat., London, 68: 293-313, 1934.

29) TARKhan, A. A. Ein experimenteller Beitrag zur Kenntnis der proprioceptiven Innervation der Zunge. Z. Anat. Entwicklungsgeschichte. 105: 349-358, 1936.

30) Weddell, G., Harpman, J. A., Lambley, D. G. and Young, L. The innervation of the musculature of the tongue. J. Anat., London, 74:255-267, 1940. 